\title{
Article
}

\section{Transcriptomic Data Analysis Reveals a Down-Expression of Galectin-8 in Schizophrenia Hippocampus}

\author{
Maria Cristina Petralia ${ }^{1}$, Rosella Ciurleo ${ }^{2}$, Alessia Bramanti ${ }^{3}$, Placido Bramanti ${ }^{2}$, Andrea Saraceno ${ }^{4}$, \\ Katia Mangano ${ }^{4}\left(\mathbb{D}\right.$, Maria Catena Quattropani ${ }^{1}$, Ferdinando Nicoletti ${ }^{4}\left(\mathbb{D}\right.$ and Paolo Fagone ${ }^{4, *(1)}$ \\ 1 Department of Clinical and Experimental Medicine, University of Messina, 98122 Messina, Italy; \\ m.cristinapetralia@gmail.com (M.C.P.); maria.quattropani@unime.it (M.C.Q.) \\ 2 IRCCS Centro Neurolesi “Bonino-Pulejo", 98124 Messina, Italy; rossella.ciurleo@irccsme.it (R.C.); \\ placido.bramanti@irccsme.it (P.B.) \\ 3 Department of Medicine, University of Salerno, 84084 Salerno, Italy; abramanti@unisa.it \\ 4 Department of Biomedical and Biotechnological Sciences, University of Catania, 95123 Catania, Italy; \\ andreasara96@gmail.com (A.S.); kmangano@unict.it (K.M.); ferdinic@unict.it (F.N.) \\ * Correspondence: paolofagone@yahoo.it
}

check for updates

Citation: Petralia, M.C.; Ciurleo, R.; Bramanti, A.; Bramanti, P.; Saraceno, A.; Mangano, K.; Quattropani, M.C.; Nicoletti, F.; Fagone, P.

Transcriptomic Data Analysis Reveals a Down-Expression of Galectin-8 in Schizophrenia Hippocampus. Brain Sci. 2021, 11, 973. https://doi.org/ 10.3390/brainsci11080973

Received: 16 June 2021

Accepted: 21 July 2021

Published: 23 July 2021

Publisher's Note: MDPI stays neutral with regard to jurisdictional claims in published maps and institutional affiliations.

Copyright: (c) 2021 by the authors. Licensee MDPI, Basel, Switzerland. This article is an open access article distributed under the terms and conditions of the Creative Commons Attribution (CC BY) license (https:/ / creativecommons.org/licenses/by/ $4.0 /)$.

\begin{abstract}
Schizophrenia (SCZ) is a severe psychiatric disorder with several clinical manifestations that include cognitive dysfunction, decline in motivation, and psychosis. Current standards of care treatment with antipsychotic agents are often ineffective in controlling the disease, as only one-third of SCZ patients respond to medications. The mechanisms underlying the pathogenesis of SCZ remain elusive. It is believed that inflammatory processes may play a role as contributing factors to the etiology of SCZ. Galectins are a family of $\beta$-galactoside-binding lectins that contribute to the regulation of immune and inflammatory responses, and previous reports have shown their role in the maintenance of central nervous system (CNS) homeostasis and neuroinflammation. In the current study, we evaluated the expression levels of the galectin gene family in post-mortem samples of the hippocampus, associative striatum, and dorsolateral prefrontal cortex from SCZ patients. We found a significant downregulation of LGALS8 (Galectin-8) in the hippocampus of SCZ patients as compared to otherwise healthy donors. Interestingly, the reduction of LGALS8 was disease-specific, as no modulation was observed in the hippocampus from bipolar nor major depressive disorder (MDD) patients. Prediction analysis identified TBL1XR1, BRF2, and TAF7 as potential transcription factors controlling LGALS8 expression. In addition, MIR3681HG and MIR4296 were negatively correlated with LGALS8 expression, suggesting a role for epigenetics in the regulation of LGALS8 levels. On the other hand, no differences in the methylation levels of LGALS8 were observed between SCZ and matched control hippocampus. Finally, ontology analysis of the genes negatively correlated with LGALS8 expression identified an enrichment of the NGF-stimulated transcription pathway and of the oligodendrocyte differentiation pathway. Our study identified LGALS8 as a disease-specific gene, characterizing SCZ patients, that may in the future be exploited as a potential therapeutic target.
\end{abstract}

Keywords: schizophrenia; hippocampus; galectins; LGALS8

\section{Introduction}

Schizophrenia (SCZ) is a severe psychiatric disorder characterized by a diverse set of clinical manifestations that include cognitive dysfunction, disorganized thinking, decline in motivation, and psychosis [1]. The global prevalence of SCZ is $\sim 1 \%$, and the incidence is approximately $1.5 / 10,000$ people [1]. Usually, the onset of SCZ is observed earlier in men, developing SCZ at age 18-25, while the onset in women is between 25 and 35 years [2]. To date, the etiology of SCZ is still elusive, and it is believed that both genetic and environmental factors may play a role, by inducing alterations in the dopaminergic, glutamatergic, serotonergic, and gamma-aminobutyric acid neurotransmitter systems [3]. 
Polymorphisms in several genes have been identified as risk factors [4,5]. The GenomeWide Association Studies (GWAS) catalog currently reports 3831 genomic associations for 105 SCZ-related traits (https://www.ebi.ac.uk/gwas/; accessed on 25 May 2021). Cortical and subcortical alterations have been described in SCZ patients, which include morphological, biochemical, and physiological aberrations [3].

A growing body of data suggests that immunologic factors exert a role in the etiology and progression of SCZ (reviewed in [6]). Significantly, increased serum levels of interleukin (IL)- 6 and of the chemokine CCL-11, as well as increased levels of IL-1 receptor antagonist and serum IL-2 receptors play a role (reviewed in [6]). In vitro production of INF- $\gamma$ and IL-4 by SCZ peripheral blood mononuclear cells (PBMCs) was found to be significantly different from controls. In first-episode psychosis patients but not in unaffected siblings, significantly increased pro- and anti-inflammatory cytokines, i.e., IL-1 $\beta$, IL-6, TNF- $\alpha$, IL-10, and TGF- $\beta$, were observed, as compared to controls [7]. Additionally, siblings presented decreased IL$1 \beta$, when compared with patients and controls [7]. Along the same lines, leukocyte m-RNA levels of IL- $1 \alpha$, IL- 6 , and TNF- $\alpha$, but not IL- $1 \beta$ and IL- 8 , were significantly increased in first-episode psychosis patients, in comparison to healthy controls, matched for age, gender, ethnicity, and body mass index [8]. Moreover, antipsychotic-naïve SCZ patients were found to have significantly higher plasma levels of IL- 6 and lower levels of IL-17 and IFN- $\gamma$ as compared with healthy controls [9]. Another study also showed that IL-6, IL-8, IL-10, and TNF- $\alpha$ positively correlated with negative psychotic symptoms, and that augmented serum levels of IL-8 are associated with poor responses to antipsychotic treatment [10].

Moreover, a significantly higher percentage of SCZ patients, as compared to controls, tested positive for anti-cardiolipin auto-antibodies (reviewed in [6]). Interestingly, positive symptoms of SCZ were associated with high levels of anti-Nerve Growth Factor (NGF) autoantibodies, while negative symptoms were associated with higher LE activity (reviewed in [6]). Other auto-antibodies, such anti-platelet, anti-muscarinic acetylcholine-receptor (mAChR), and anti- $\alpha-7$ subunit of the acetylcholine nicotinic receptor $(\alpha 7 \mathrm{AChNR})$, were more frequently observed in SCZ patients than controls. Finally, a significant genome association was found between SCZ and the MHC locus on chromosome 6, as well as the IL-2 single nucleotide polymorphism (SNP) of the TT genotype and the IL-4 SNP of the CC genotype (reviewed in [6]).

Galectins are a family of $\beta$-galactoside-binding lectins that take part in several biological processes, such cell adhesion and motility, autophagy, proliferation, angiogenesis, cell signaling, immune responses, and inflammation [11]. Galectins are small soluble proteins that contain either one or two carbohydrate recognition domains (CRDs). Galectins are present in both the cytosol and nucleus, as well as in the extracellular compartment, as they are secreted by a non-classical secretion process, which bypasses the Golgi complex [11]. Increasing data suggest that galectins, such as Galectin-1 and Galectin-3, are involved in the regulation of CNS homeostasis and neuroinflammation by regulating microglial activation, dampening neurodegeneration, and favoring neuroprotection [12]. Galectin-1, Galectin-3, Galectin-4, Galectin-8, and Galectin-9 are highly expressed in the brain [13]; however, to date, most studies on CNS function and protection have been dedicated to Galectin-1 and Galectin-3 [14].

In the present study, we investigated the expression levels of the galectin gene family members in post-mortem samples of different brain regions of SCZ patients, as compared to matched control and bipolar and major depressive disorder (MDD) patients as well. We found a significant downregulation of LGALS8 (Galectin-8) in the hippocampus of SCZ patients, in comparison to otherwise healthy donors. Interestingly, the down-expression of LGALS8 was disease-specific, as no modulation was observed in the hippocampus from the bipolar nor MDD hippocampus. Moreover, ontology analysis of the genes negatively correlated with LGALS8 expression identified an enrichment of the NGF-stimulated transcription pathway and of the oligodendrocyte differentiation pathway. 


\section{Materials and Methods}

\subsection{Dataset Selection and Analysis}

The NCBI Gene Expression Omnibus (GEO) database (http:/ / www.ncbi.nlm.nih.gov / geo/, accessed on 2 March 2021) was used to identify microarray datasets comparing the transcriptomic profiles of brain from healthy donors and SCZ patients. The GEO database was manually searched using the MeSH term (Medical Subject Headings) "schizophrenia". The datasets were selected if they met the following inclusion criteria: (a) whole-genome transcriptomic profiling; (b) tissues collected from defined brain regions; (c) consisted of both one cohort of SCZ patients and another cohort of healthy people; and (d) species of origin "Homo sapiens". Finally, the GSE53987 was selected for the analysis, as it included whole genome transcriptomic data from post-mortem samples of hippocampus, associative striatum, and dorsolateral prefrontal cortex from SCZ patients, as well as control subjects and patients suffering from bipolar disorder and major depressive disorder (MDD) [15]. The clinical data available for the patients included in the GSE53987 dataset are summarized in Table 1. Briefly, the GSE53987 dataset included 19 samples from healthy people, 15 samples from SCZ patients, 18 samples from bipolar patients, and 17 from MDD patients [15]. Data were subjected to quantile normalization, and low variance genes were excluded from the analysis. For this study, the expression levels of LGALS1, LGALS2, LGALS3, LGALS3BP , LGALS4, LGALS8, LGALS9, LGALS12, LGALS13, and LGALS14 were evaluated.

Table 1. Clinical data of patients included in GSE53987.

\begin{tabular}{ccccc}
\hline & Control & Bipolar & Major Depressive Disorder & Schizophrenia \\
\hline Sex $(\mathrm{M} / \mathrm{F})$ & $10 / 9$ & $10 / 9$ & $10 / 9$ & $10 / 9$ \\
\hline $\begin{array}{c}\text { Race } \\
\text { (Caucasian/Afro-American) }\end{array}$ & $18 / 1$ & $19 / 0$ & $18 / 1$ & $13 / 6$ \\
\hline Age (years) & $48.1 \pm 10.6$ & $46.3 \pm 9.5$ & $45.2 \pm 10.1$ & $45.1 \pm 8.5$ \\
\hline
\end{tabular}

\subsection{Gene Ontology Analysis}

Pathway analysis, Gene Ontology, and interactome analysis were performed using the online software Metascape [16]. The hypergeometric test and Benjamini-Hochberg $p$-value correction are used to identify significant enriched ontology terms. Metascape analysis relies on several databases, including KEGG, MSigDB, Gene Ontology, and Reactome, among the others. Enriched terms are clustered into non-redundant groups, by calculating the pairwise similarity between the enriched terms, using a Kappa-test score [16].

\subsection{Gene Expression Regulation}

For the identification of the transcription factors (TFs) that could regulate the expression of LGALS8, a list of putative TFs was first retrieved from John and Mishra (2016) [17]. The TFs mostly correlated (FDR < 0.05) to LGALS8 expression were then clustered using the Spearman rank correlation, as similarity metrics. For the identification of miRNAs putatively regulating LGALS8 expression, the miRWalk database was interrogated ( http:/ / mirwalk.umm.uni-heidelberg.de/, accessed on 23 July 2021). Among the predicted miRNAs, those negatively correlated to LGALS8 expression were selected. For the analysis of the methylation pattern of LGALS8, the GSE89703 dataset was interrogated. The dataset included post-mortem hippocampus samples: 14 schizophrenia and 13 controls. Bisulfite converted DNA from these samples were hybridized to the Illumina Infinium 450k Human Methylation Beadchip v1.0 [18]. 


\subsection{Statistical Analysis}

Statistical analysis for the microarray data was performed using the LIMMA (Linear Model for MicroArray Analysis) test. An adjusted (Benjamini-Hochberg corrected) $p$ value (adj. $p$-value, FDR: False Discovery Rate) $<0.05$ was considered as threshold for statistical significance. Hierarchical clustering and gene similarity matrix were calculated using the Spearman rank correlation, as similarity metrics. For the identification of the genes significantly correlated to LGALS8, the Pearson correlation was calculated, and the statistical significance was computed using a permutation test, with 1000 random permutations. Correlated genes were selected based on $p$-value $<0.01$ and $|\mathrm{r}|>0.7$.

\section{Results}

Expression Levels of the Galectin Gene Family Members in Different Brain Regions from Control Donors

First, we wanted to determine the expression levels of the galectin gene family members in different brain areas from control donors. As shown in Figure 1, significant differences could be observed in the expression levels of the galectins in the hippocampus, associative striatum, and the prefrontal cortex (Figure 1A). In particular, the hippocampus was characterized by a down-expression of LGALS1, LGALS13, and LGALS14, as compared to striatum and prefrontal cortex. An over-expression of LGALS1 and LGALS8 was instead observed in the prefrontal cortex, as compared to the hippocampus and striatum. Significant higher levels of $L G A L S 3, L G A L S 3 B P$, and LGALS14, as well as significant lower levels of LGALS2, LGALS8, LGALS9, and LGALS12 characterized the associative striatum when compared to the hippocampus and the prefrontal cortex (Figure 1A). Along the same lines, hierarchical cluster analysis revealed that the hippocampus, prefrontal cortex, and striatum could be segregated by considering the expression levels of the galectin gene family members (Figure 1B). 
A

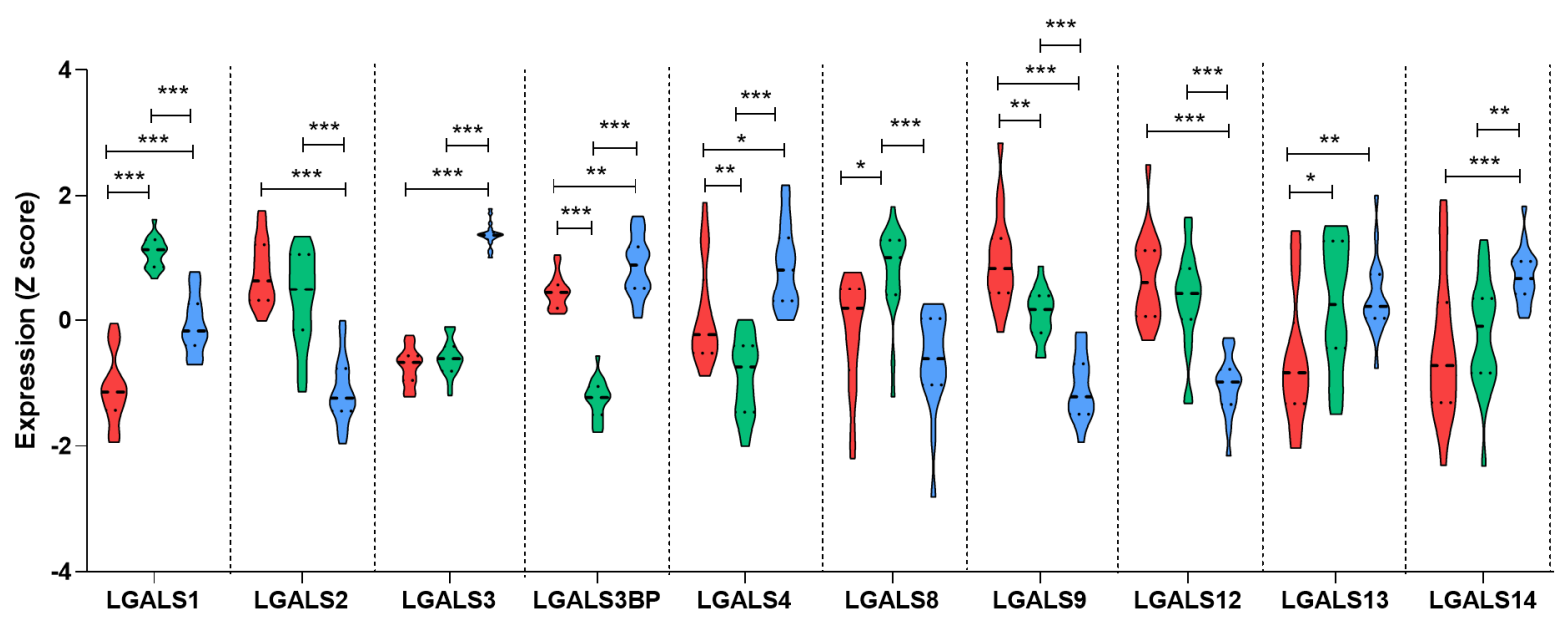

${ }^{*} \mathrm{FDR}<0.05 ;{ }^{* *} \mathrm{FDR}<0.01 ;{ }^{* * *} \mathrm{FDR}<0.001$

B
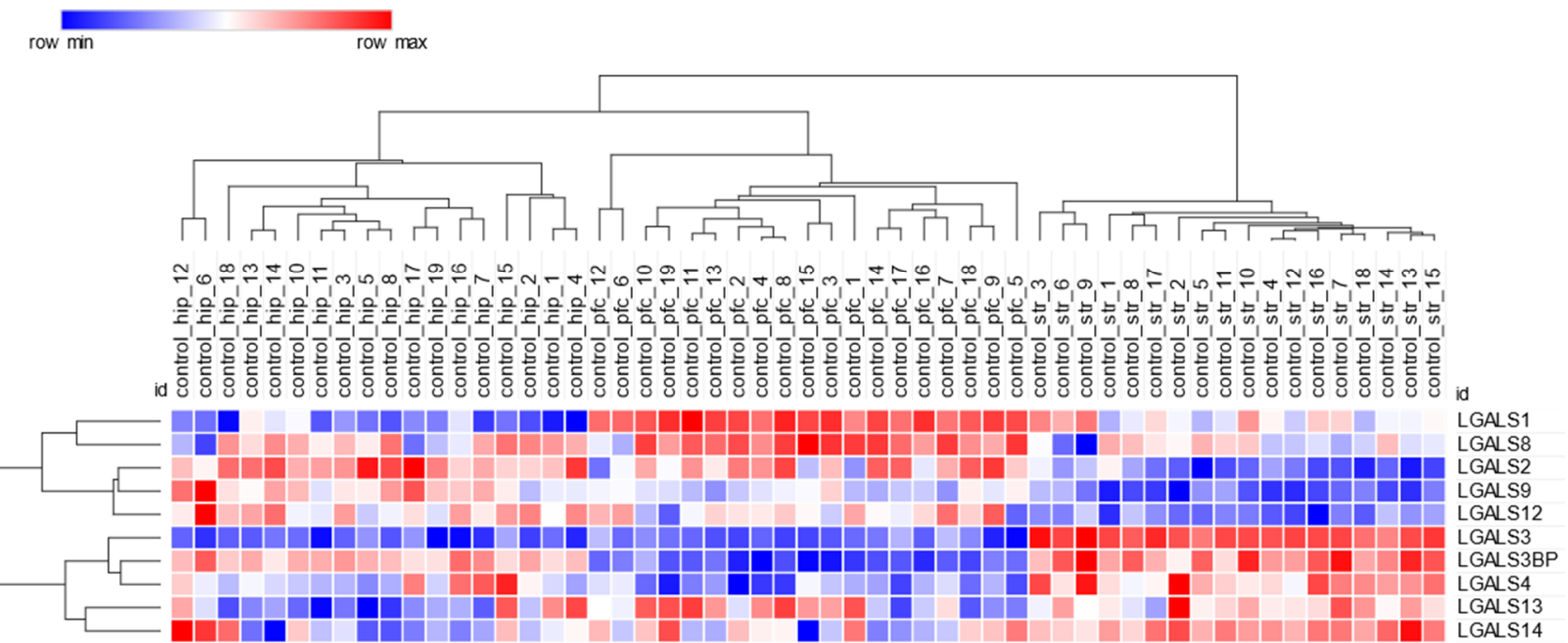

Figure 1. Expression levels of the galectin gene family members in the normal brain. The expression levels of the members of the galectin gene family were determined by interrogating the GSE53987 dataset. (A) Violin plots showing the expression levels of the galectin genes in the hippocampus, prefrontal cortex, and striatum of normal donors. (B) Hierarchical clustering for the expression levels of the galectin genes; the hippocampus, prefrontal cortex, and striatum of normal donors were calculated using the Spearman rank correlation as similarity metrics.

Next, we determined the relative expression levels of the different members of the galectin family in SCZ patients. As shown in Figure 2, only LGALS8 was significantly downregulated in the hippocampus of SCZ patients, as compared to the control donors (Figure 2). Interestingly, no modulation of LGALS8 was observed in either the bipolar or the MDD hippocampus samples (Figure 2). A trend of reduced levels of LGALS8 was also observed in the striatum and the prefrontal cortex from SCZ patients, but statistical significance was not reached. No modulation was observed in the expression levels of all the other members of the galectin family, in either of the brain areas considered and for either the bipolar or MDD patients (Figure 2) 


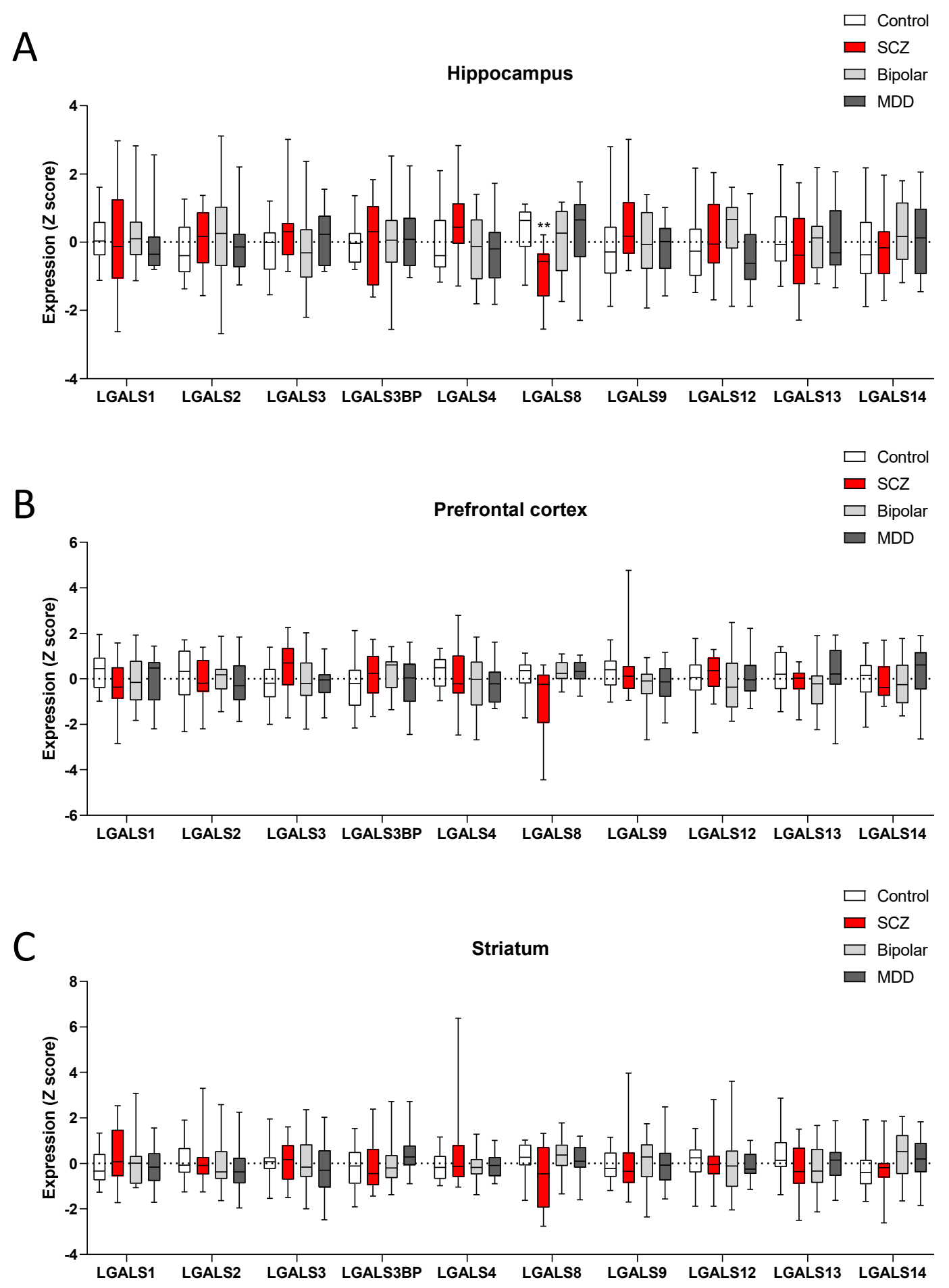

Figure 2. Expression levels of galectin gene family members in the SCZ brain. The expression levels of the members of the galectin gene family were determined by interrogating the GSE53987 dataset. (A) Expression levels of the galectin genes in post-mortem samples of the hippocampus from control donors, and SCZ, bipolar, and MDD patients. (B) Expression levels of the galectin genes in post-mortem samples of the prefrontal cortex from control donors, and SCZ, bipolar, and MDD patients. (C) Expression levels of the galectin genes in post-mortem samples of the striatum from control donors, and SCZ, bipolar, and MDD patients.

Since all the SCZ patients were under antipsychotic treatment, we aimed to determine whether the modulation in LGALS8 expression was related to drug exposure rather than to the disease. To this aim, we interrogated the GSE66277, which included whole-genome 
expression data from male Sprague-Dawley rats chronically treated with either haloperidol, risperidone, or vehicle. No modulation of LGALS8 was observed in the hippocampus of the treated rats (Supplementary Materials Figure S1).

Next, we wanted to determine the mechanisms of regulation of LGALS8 expression in the SCZ hippocampus. As shown in Figure $3 \mathrm{~A}$, among the putative TFs regulating LGALS8 expression, TBL1XR1, BRF2, and TAF7 were the most positively correlated TFs (FDR < 0.05) (Figure 3A). Moreover, among the miRNAs predicted for LGALS8, two of them, i.e., MIR3681HG and MIR4296, were negatively correlated with LGALS8 expression, suggesting a role for epigenetics in the regulation of LGALS8 levels (Figure 3B). On the other hand, no significant differences were observed in the methylation levels of LGALS8 between SCZ and matched control donor hippocampus (Figure 3C).

A
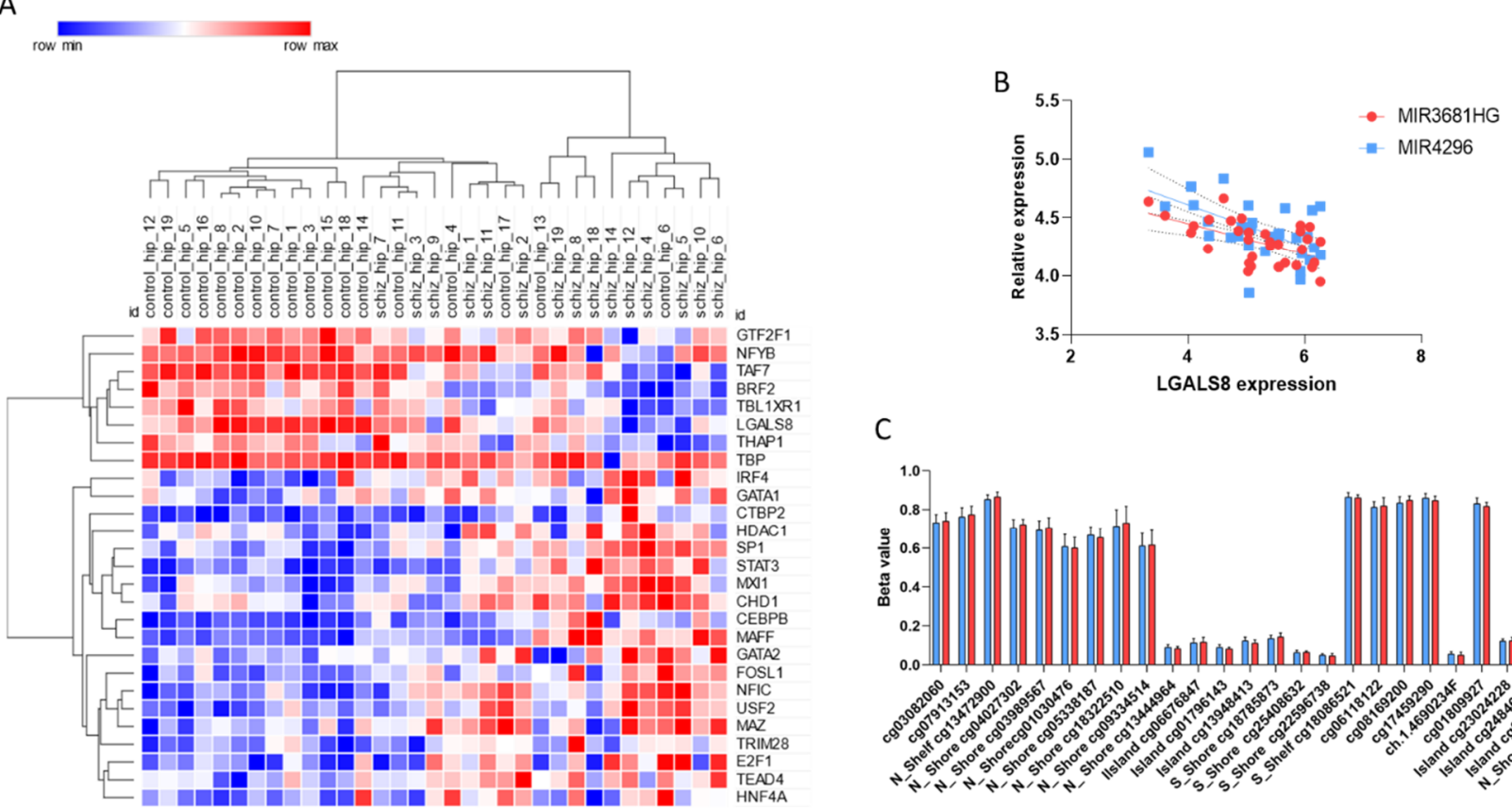

C

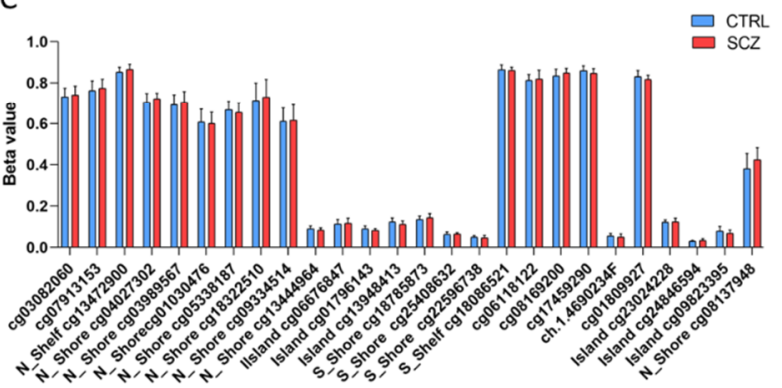

Figure 3. Regulation of LGALS8 expression in SCZ brain. (A) Hierarchical clustering of the transcription factors predicted for LGALS8 in the SCZ hippocampus, as determined in the GSE53987 dataset. (B) Correlation between LGALS8 expression and MIR3681HG and MIR4296, as determined in the GSE53987 dataset. (C) Methylation levels of the LGALS8 gene in the hippocampus from SCZ patients and control donors, as determined in the GSE89703 dataset.

Finally, to gain insights into the biological meaning of LGALS8 modulation in the SCZ hippocampus, we first identified the genes significantly correlated, both positively and negatively, to LGALS8 expression, and Gene Ontology and pathway analysis were performed. In total, 115 genes were negatively correlated, while 177 genes were positively correlated to LGALS8 ( $p$-value $<0.01$ and $|\mathrm{r}|>0.7$ ). Several enriched terms were found for both the positively and negatively correlated genes (Figures 4 and 5). In particular, R-HSA9031628 (NGF-stimulated transcription), GO:0048709 (oligodendrocyte differentiation), and GO:0070848 (response to growth factor) were found to be enriched among the genes negatively correlated to LGALS8, while GO:0043266 (regulation of potassium ion transport), GO:0032984 (protein-containing complex disassembly), and GO:0042180 (cellular ketone metabolic process) were found to be enriched among the genes positively correlated to LGALS8 (Figures 4 and 5). 


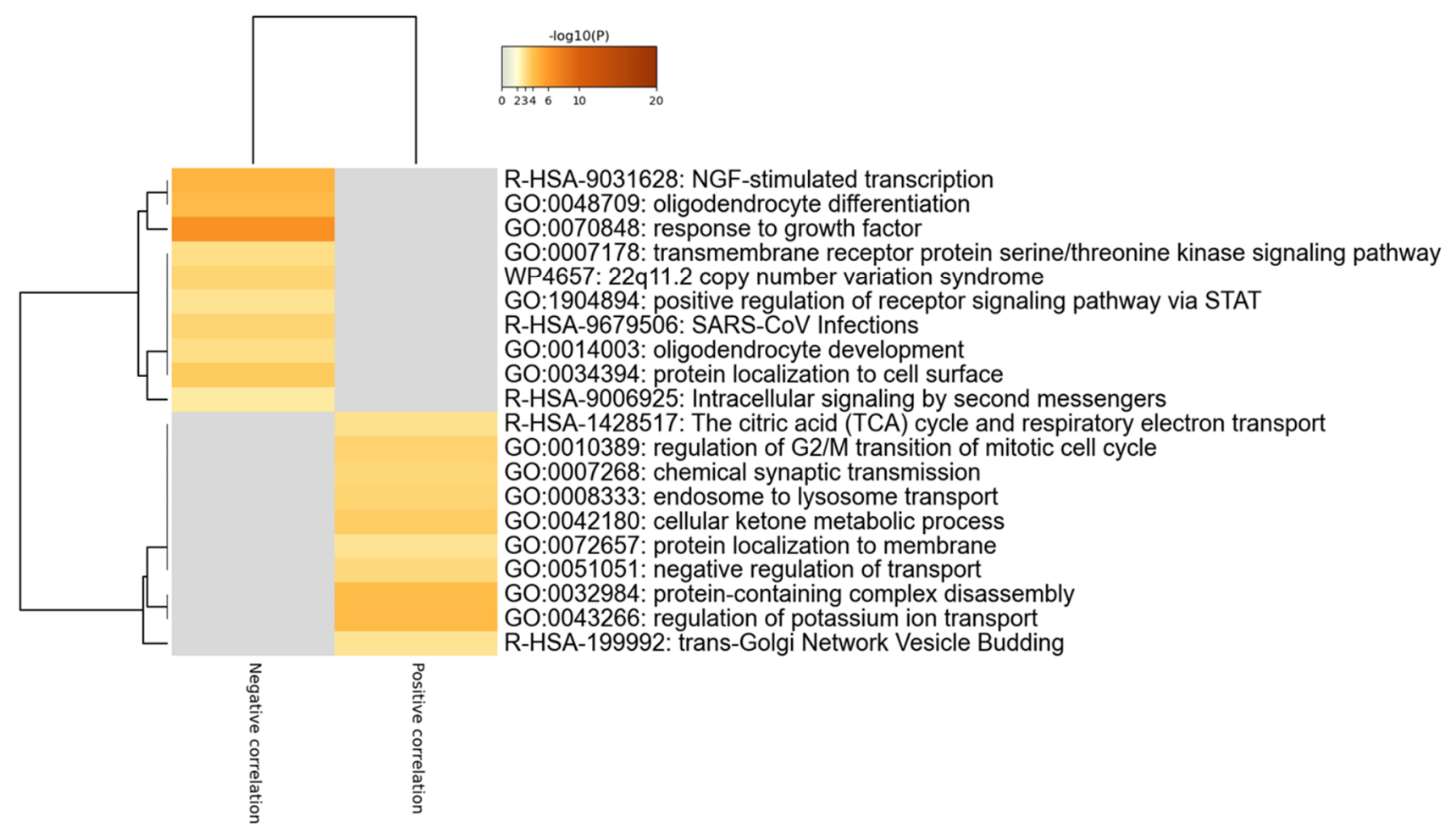

Figure 4. Gene Ontology and pathway analysis for the genes most correlating with LSGALS8 in SCZ hippocampus. Genes significantly correlated to LSGALS8 in SCZ hippocampus were identified by calculating the Pearson correlation, and the statistical significance was computed using a permutation test, with 1000 random permutations. The graph represents the hierarchical clustering of the most enriched biological processes and gene ontologies among the genes significantly correlated to LGALS8, as determined using the web-based utility, Metascape.

A

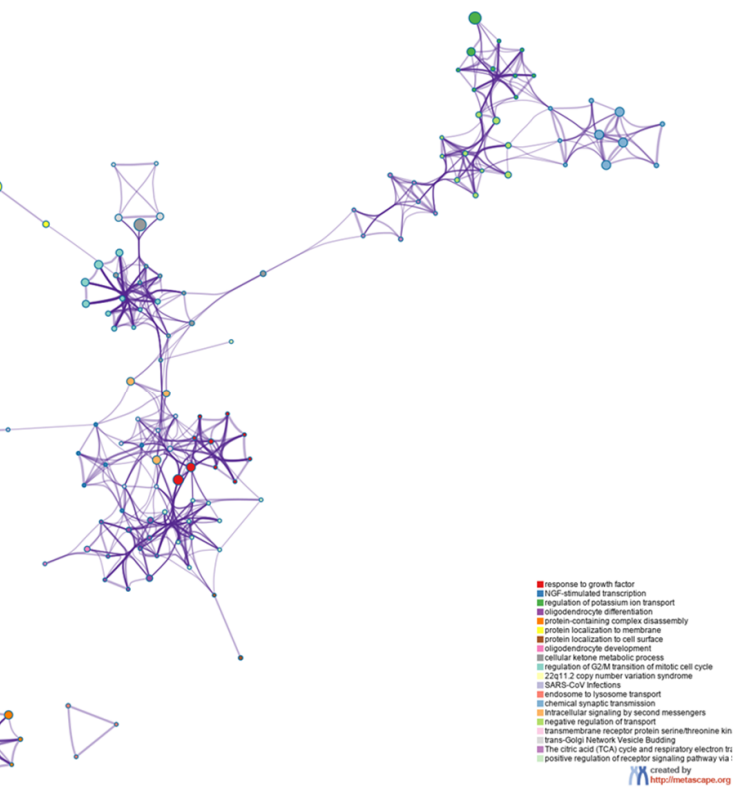

B

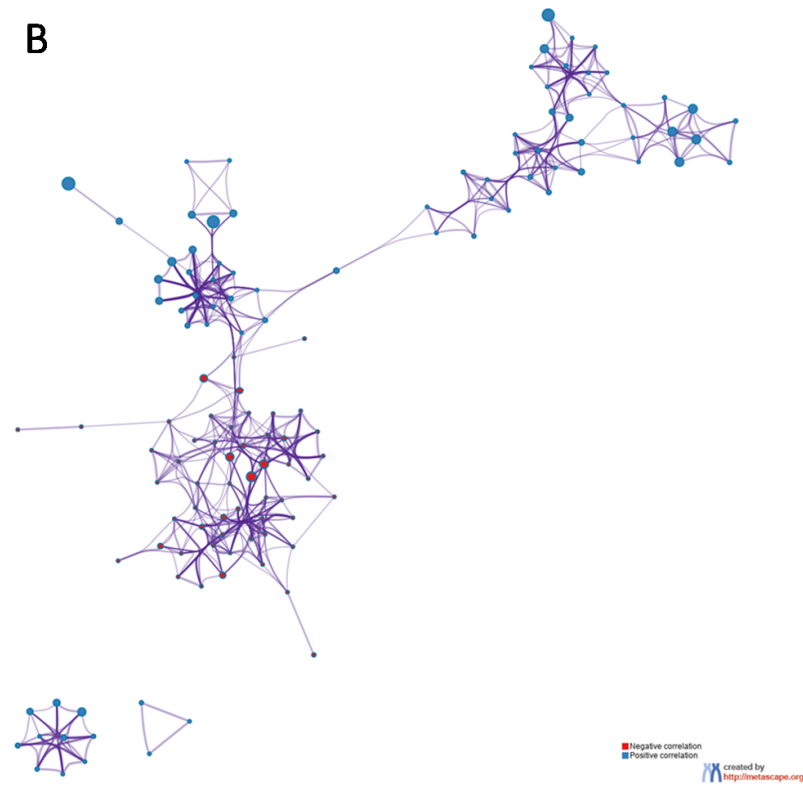

Figure 5. Enrichment analysis for the genes most correlating with LSGALS8 in SCZ hippocampus. Genes significantly correlated to LSGALS8 in SCZ hippocampus were identified by calculating the Pearson correlation, and the statistical significance was computed using a permutation test, with 1000 random permutations. (A) Network showing the interconnection among the most enriched terms. Each term is represented by a circle node, with a size proportional to the number of genes that fall into each term, and the color representing the cluster identity; (B) the same network with the nodes colored based on whether the specific enriched term is enriched by either the genes positively (blue) or negatively (red) correlated to LGALS8. 


\section{Discussion}

Dysfunction in the prefrontal cortex, hippocampus, and associative striatum has been described for several psychiatric diseases, including SCZ [15,19-22]. Previous reports have shown differential expression of multiple genes across brain regions in SCZ patients, as compared with control donors $[15,19]$. In these studies, the hippocampus has shown the highest number of transcriptional changes in SCZ [15,19]. The most striking result of these studies is the consistent upregulation of inflammatory pathways in the brain of SCZ subjects [23]. Interestingly, on the other hand, bipolar and MDD samples showed very little enrichment of the same inflammatory pathways [15,19].

The finding of the inflammatory dysregulation underlying SCZ has prompted significant interest in testing the immunomodulatory potential of psychotropic medications. Unfortunately, discordant results have been obtained among studies, which dampens the possibility of reaching conclusive results [24]. Additionally, clinical trials on the effects of anti-inflammatory drugs have shown mixed benefit in patients with SCZ [25]. This is likely due to the low passage of most current anti-inflammatory drugs across the blood-brain barrier (BBB). Hence, strategies to enhance the BBB permeation of drugs aimed at reducing neuroinflammation may represent in the future a viable therapeutic strategy for treating SCZ. It is also likely that earlier intervention may be more effective, as the persistence of inflammation in the adult SCZ brain could cut down the possibility of producing measurable improvements, when prolonged inflammatory processes cause irreversible structural alterations in the brain circuitry.

The role of inflammation in the pathogenesis of SC is supported by animal models showing that prenatal immune activation determines a series of brain alterations, such as reduction in parvalbumin interneurons, disrupted working memory, and alteration in both NMDA and dopamine signaling, which are relevant to SCZ [26,27]. Moreover, animal exposure to an acute prenatal immune activation is associated with persistent increases in cytokine production in the frontal cortex and hippocampus of young adult animals $[28,29]$.

In accordance with the role of inflammation in SCZ (reviewed in [6]), it was shown that following treatment of the acute illness, IL-6 levels significantly decreased in SCZ patients, along with an increase in sIL-2R [30]. In another meta-analysis, brain-derived neurotrophic factor (BDNF) increased upon treatment in SCZ along with a decrease in serum IL6 and TNF- $\alpha$ concentrations [31]. Additionally, after risperidone treatment, IL-6, IL-10, TNF- $\alpha$, and IL-4 decreased significantly [32]. No significant differences were found between the post-treatment cytokine levels in first episode psychosis patients and in healthy controls, suggesting that these patterns of altered cytokine levels may represent a marker of first episode psychosis [32]. In addition, there was a significant negative association between the risperidone-induced changes in IL-10 and the negative symptoms [32].

In the present study, by making use of a publicly available transcriptomic dataset, we observed a significant downregulation of LGALS8 in the hippocampus from SCZ patients, which negatively correlated to genes involved in the regulation of oligodendrocyte development and response to NGF. The use of whole-genome expression databases has been largely exploited by our group and others [33-37] for the characterization of pathogenic pathways and to identify therapeutic targets for a variety of disorders, such as autoimmune diseases [38-46] and cancer $[40,47,48]$ and has allowed pathogenic pathways [49-52] and potential therapeutic targets [53-57] to be characterized.

Galectin- 8 belongs to the tandem-repeat class of galectins characterized by two CRDs, which are linked by peptides of varying length $[58,59]$. Unlike the other galectins, Galectin-8 specifically binds the $\alpha 2,3$-sialylated glycans via its $\mathrm{N}$-terminal CRD [58,59]. Intracellularly, Galectin-8, by binding the cytosolic exposed luminal glycans of damaged endosomes and lysosomes to the NDP52 autophagy adaptor, promotes their autophagic removal [60]. This function represents a defense mechanism against infections and seems to protect against the aggregation of the tau protein, involved in the pathogenesis of Alzheimer's disease [60-63]. In the extracellular compartment, Gal-8 binds $\beta 1$-integrins and activates the downstream ERK1/2 and PI3K/AKT signaling pathways [64-66]. Pardo and colleagues have shown 
in vitro that Galectin-8 protects hippocampal neurons against stress, including nutrient deprivation, oxidative stress, $\beta$-amyloid oligomers exposure, and glutamate-induced excitotoxicity [67]. In culture, primary hippocampal neurons secrete Galectin-8, and, in vitro, anti-Galectin-8 auto-antibodies from Systemic Lupus Erythematosus patients affect neuron survival [67]. Finally, higher levels of apoptosis are observed in the hippocampus from Galectin-8 knockout mice, upon local injection of hydrogen peroxide, suggesting the neuroprotective effect of Galectin-8 in the hippocampus [67]. Hence, it is possible that the down-expression of LGALS8 observed in the postmortem SCZ hippocampus is not a downstream result of pathological processes but could be itself a mediator of the disease.

It should be noted that the reduction of LGALS8 was disease- and region-specific, as no modulation was observed in the hippocampus from bipolar nor MDD patients, nor in the associative striatum and prefrontal cortex. This is in line with the observation that the greatest regional burden of transcriptional changes was different among SCZ, bipolar, and MDD subjects [15]. In particular, it was observed that MDD samples showed more differentially expressed genes in the striatum and hippocampus than in the prefrontal cortex, whereas a lower number of transcripts were altered in the striatum from BD patients [15]. Additionally, the most dramatic alterations were found for SCZ subjects in all of the brain regions studied, when compared to BD and MDD samples. Indeed, the hippocampus showed the highest number of transcriptomic changes in SCZ, while the lower number of differentially expressed genes was detected in the prefrontal cortex $[15,68,69]$. It is also interesting to note that among the altered biological pathways underlying SCZ [70], several of them were enriched by the DEGs significantly correlated to LGALS8 expression, including cell cycle proliferation, survival, and ion channel homeostasis.

The analysis of the hippocampus from rats chronically administered with antipsychotic drugs showed no modulation in LGALS8 expression. These data suggest that the modulation of LGALS8 in SCZ may not be dependent on medication and could instead independently underlie SCZ pathology. However, there are some points that need to be addressed: the analysis of the rat hippocampus was performed on animals treated with either risperidone or haloperidol. Hence, we may have missed the effect of other antipsychotic medications and also the effect of their combined administration, which is common for psychiatric patients. Moreover, the medications were dosed to healthy rats, without neurological conditions resembling SCZ pathology. Finally, differences in the metabolism between rats and humans could have biased our observation. One final limitation of this study is that bulk transcriptomic data were used for this study. Hence, future studies will need to focus on cell-specific changes, which may help to clarify the cell populations within the hippocampus undergoing the modulation of LGALS8, and the consequences to the other cellular populations. Additionally, the enrollment of larger cohorts of patients will help to better correlate the observed transcriptional change to the symptoms of SCZ and its progression.

\section{Conclusions}

Overall, with the present study, we are providing a comprehensive view of the expression levels of the different members of the galectin gene family in different brain areas of patients with SCZ. The significant reduced levels of LGALS8 observed in the hippocampus from SCZ patients appears to be a disease-specific hallmark of SCZ. However, whether this modulation of LGALSB is a driver of the disease or a consequence of genetic/epigenetic factors remains to be determined. Upon the precise identification of the LGALS8-related pathways underlying SCZ pathogenesis, the use of drug discovery approaches will help to design tailored pharmacological strategies that may regulate these pathways.

Supplementary Materials: The following are available online at https: / www.mdpi.com/article/ 10.3390/brainsci11080973/s1, Figure S1: Effect of chronic anti-psychotic treatment on Galectin-8 expression in rat hippocampus. 
Author Contributions: Conceptualization, M.C.P., F.N., and P.F.; Data curation, A.B., P.B., A.S., K.M. and P.F.; Formal analysis, M.C.P., R.C., K.M. and P.F.; Investigation, M.C.P., R.C., A.B., A.S., K.M. and M.C.Q.; Methodology, F.N.; Project administration, P.B.; Resources, P.B.; Supervision, F.N.; Writing-original draft, M.C.P. and R.C.; Writing—review and editing, A.B., P.B., K.M., M.C.Q., F.N. and P.F. All authors have read and agreed to the published version of the manuscript.

Funding: This research was funded by IRCCS “Centro Neurolesi Bonino-Pulejo", Current Research Funds 2021.

Institutional Review Board Statement: Not applicable.

Informed Consent Statement: Not applicable.

Data Availability Statement: All data are available from the GSE53987 dataset, freely available from the Gene Expression Omnibus (GEO) database.

Conflicts of Interest: The authors declare no conflict of interest.

\section{References}

1. Mueser, K.T.; McGurk, S.R. Schizophrenia. Lancet 2004, 363, 2063-2072. [CrossRef]

2. McGrath, J.; Saha, S.; Chant, D.; Welham, J. Schizophrenia: A concise overview of incidence, prevalence, and mortality. Epidemiol. Rev. 2008, 30, 67-76. [CrossRef]

3. Guillozet-Bongaarts, A.L.; Hyde, T.M.; Dalley, R.A.; Hawrylycz, M.J.; Henry, A.; Hof, P.R.; Hohmann, J.; Jones, A.R.; Kuan, C.L.; Royall, J.; et al. Altered gene expression in the dorsolateral prefrontal cortex of individuals with schizophrenia. Mol. Psychiatry 2014, 19, 478-485. [CrossRef] [PubMed]

4. Duan, J.; Sanders, A.R.; Gejman, P.V. Genome-wide approaches to schizophrenia. Brain Res. Bull. 2010, 83, 93-102. [CrossRef] [PubMed]

5. Kleinman, J.E.; Law, A.J.; Lipska, B.K.; Hyde, T.M.; Ellis, J.K.; Harrison, P.J.; Weinberger, D.R. Genetic neuropathology of schizophrenia: New approaches to an old question and new uses for postmortem human brains. Biol. Psychiatry 2011, 69, 140-145. [CrossRef]

6. Richard, M.D.; Brahm, N.C. Schizophrenia and the immune system: Pathophysiology, prevention, and treatment. Am. J. Heal. Pharm. 2012, 69, 757-766. [CrossRef] [PubMed]

7. Corsi-Zuelli, F.; Loureiro, C.M.; Shuhama, R.; Fachim, H.A.; Menezes, P.R.; Louzada-Junior, P.; Mondelli, V.; Del-Ben, C.M. Cytokine profile in first-episode psychosis, unaffected siblings and community-based controls: The effects of familial liability and childhood maltreatment. Psychol. Med. 2020, 50, 1139-1147. [CrossRef] [PubMed]

8. Di Nicola, M.; Cattaneo, A.; Hepgul, N.; Di Forti, M.; Aitchison, K.J.; Janiri, L.; Murray, R.M.; Dazzan, P.; Pariante, C.M.; Mondelli, V. Serum and gene expression profile of cytokines in first-episode psychosis. Brain. Behav. Immun. 2013, 31, 90-95. [CrossRef] [PubMed]

9. Kalmady, S.V.; Shivakumar, V.; Jose, D.; Ravi, V.; Keshavan, M.S.; Gangadhar, B.N.; Venkatasubramanian, G. Plasma cytokines in minimally treated schizophrenia. Schizophr. Res. 2018, 199, 292-296. [CrossRef]

10. Enache, D.; Nikkheslat, N.; Fathalla, D.; Morgan, B.P.; Lewis, S.; Drake, R.; Deakin, B.; Walters, J.; Lawrie, S.M.; Egerton, A.; et al. Peripheral immune markers and antipsychotic non-response in psychosis. Schizophr. Res. 2021, 230, 1-8. [CrossRef]

11. Johannes, L.; Jacob, R.; Leffler, H. Galectins at a glance. J. Cell Sci. 2018, 131. [CrossRef] [PubMed]

12. Yüksel, R.N.; Göverti, D.; Kahve, A.C.; Çakmak, I.B.; Yücel, Ç.; Göka, E. Galectin-1 and galectin-3 levels in patients with schizophrenia and their unaffected siblings. Psychiatr. Q. 2020, 91, 715-725. [CrossRef] [PubMed]

13. Stancic, M.; van Horssen, J.; Thijssen, V.L.; Gabius, H.-J.; van der Valk, P.; Hoekstra, D.; Baron, W. Increased expression of distinct galectins in multiple sclerosis lesions. Neuropathol. Appl. Neurobiol. 2011, 37, 654-671. [CrossRef]

14. Siew, J.J.; Chern, Y. Microglial lectins in health and neurological diseases. Front. Mol. Neurosci. 2018, 11, 158. [CrossRef] [PubMed]

15. Lanz, T.A.; Reinhart, V.; Sheehan, M.J.; Rizzo, S.J.S.; Bove, S.E.; James, L.C.; Volfson, D.; Lewis, D.A.; Kleiman, R.J. Postmortem transcriptional profiling reveals widespread increase in inflammation in schizophrenia: A comparison of prefrontal cortex, striatum, and hippocampus among matched tetrads of controls with subjects diagnosed with schizophrenia, bipolar or major depressive disorder. Transl. Psychiatry 2019, 9, 151. [CrossRef] [PubMed]

16. Zhou, Y.; Zhou, B.; Pache, L.; Chang, M.; Khodabakhshi, A.H.; Tanaseichuk, O.; Benner, C.; Chanda, S.K. Metascape provides a biologist-oriented resource for the analysis of systems-level datasets. Nat. Commun. 2019, 10, 1523. [CrossRef] [PubMed]

17. John, S.; Mishra, R. mRNA transcriptomics of galectins unveils heterogeneous organization in mouse and human brain. Front. Mol. Neurosci. 2016, 9, 139. [CrossRef] [PubMed]

18. Viana, J.; Hannon, E.; Dempster, E.; Pidsley, R.; Macdonald, R.; Knox, O.; Spiers, H.; Troakes, C.; Al-Saraj, S.; Turecki, G.; et al. Schizophrenia-associated methylomic variation: Molecular signatures of disease and polygenic risk burden across multiple brain regions. Hum. Mol. Genet. 2017, 26, 210-225. [CrossRef] 
19. Petralia, M.C.; Ciurleo, R.; Saraceno, A.; Pennisi, M.; Basile, M.S.; Fagone, P.; Bramanti, P.; Nicoletti, F.; Cavalli, E. Meta-analysis of transcriptomic data of dorsolateral prefrontal cortex and of peripheral blood mononuclear cells identifies altered pathways in schizophrenia. Genes 2020, 11, 390. [CrossRef]

20. Henseler, I.; Falkai, P.; Gruber, O. Disturbed functional connectivity within brain networks subserving domain-specific subcomponents of working memory in schizophrenia: Relation to performance and clinical symptoms. J. Psychiatr. Res. 2010, 44, 364-372. [CrossRef]

21. Benetti, S.; Mechelli, A.; Picchioni, M.; Broome, M.; Williams, S.; McGuire, P. Functional integration between the posterior hippocampus and prefrontal cortex is impaired in both first episode schizophrenia and the at risk mental state. Brain 2009, 132, 2426-2436. [CrossRef] [PubMed]

22. Meyer-Lindenberg, A.; Miletich, R.S.; Kohn, P.D.; Esposito, G.; Carson, R.E.; Quarantelli, M.; Weinberger, D.R.; Berman, K.F. Reduced prefrontal activity predicts exaggerated striatal dopaminergic function in schizophrenia. Nat. Neurosci. 2002, 5, 267-271. [CrossRef] [PubMed]

23. Saetre, P.; Emilsson, L.; Axelsson, E.; Kreuger, J.; Lindholm, E.; Jazin, E. Inflammation-related genes up-regulated in schizophrenia brains. BMC Psychiatry 2007, 7. [CrossRef] [PubMed]

24. Baumeister, D.; Ciufolini, S.; Mondelli, V. Effects of psychotropic drugs on inflammation: Consequence or mediator of therapeutic effects in psychiatric treatment? Psychopharmacology 2016, 233, 1575-1589. [CrossRef] [PubMed]

25. Keller, W.R.; Kum, L.M.; Wehring, H.J.; Koola, M.M.; Buchanan, R.W.; Kelly, D.L. A review of anti-inflammatory agents for symptoms of schizophrenia. J. Psychopharmacol. 2013, 27, 337-342. [CrossRef]

26. Macêdo, D.S.; Araújo, D.P.; Sampaio, L.R.L.; Vasconcelos, S.M.M.; Sales, P.M.G.; Sousa, F.C.F.; Hallak, J.E.; Crippa, J.A.; Carvalho, A.F. Animal models of prenatal immune challenge and their contribution to the study of schizophrenia: A systematic review. Braz. J. Med. Biol. Res. 2012, 45, 179-186. [CrossRef]

27. Meyer, U.; Feldon, J.; Schedlowski, M.; Yee, B.K. Towards an immuno-precipitated neurodevelopmental animal model of schizophrenia. Neurosci. Biobehav. Rev. 2005, 29, 913-947. [CrossRef]

28. Garay, P.A.; Hsiao, E.Y.; Patterson, P.H.; McAllister, A.K. Maternal immune activation causes age- and region-specific changes in brain cytokines in offspring throughout development. Brain. Behav. Immun. 2013, 31, 54-68. [CrossRef]

29. Giovanoli, S.; Engler, H.; Engler, A.; Richetto, J.; Voget, M.; Willi, R.; Winter, C.; Riva, M.A.; Mortensen, P.B.; Schedlowski, M.; et al. Stress in puberty unmasks latent neuropathological consequences of prenatal immune activation in mice. Science 2013, 339, 1100-1102. [CrossRef]

30. Goldsmith, D.R.; Rapaport, M.H.; Miller, B.J. A meta-analysis of blood cytokine network alterations in psychiatric patients: Comparisons between schizophrenia, bipolar disorder and depression. In Molecular Psychiatry; Nature Publishing Group: London, UK, 2016; Volume 21, pp. 1696-1709.

31. Çakici, N.; Sutterland, A.L.; Penninx, B.W.J.H.; De Haan, L.; Van Beveren, N.J.M. Changes in peripheral blood compounds following psychopharmacological treatment in drug-naïve first-episode patients with either schizophrenia or major depressive disorder: A meta-analysis. Psychol. Med. 2021, 51, 538-549. [CrossRef]

32. Noto, C.; Ota, V.K.; Gouvea, E.S.; Rizzo, L.B.; Spindola, L.M.N.; Honda, P.H.S.; Cordeiro, Q.; Belangero, S.I.; Bressan, R.A.; Gadelha, A.; et al. Effects of risperidone on cytokine profile in drug-naive first-episode psychosis. Int. J. Neuropsychopharmacol. 2015, 18, pyu042. [CrossRef]

33. Candido, S.; Lupo, G.; Pennisi, M.; Basile, M.; Anfuso, C.; Petralia, M.; Gattuso, G.; Vivarelli, S.; Spandidos, D.; Libra, M.; et al. The analysis of miRNA expression profiling datasets reveals inverse microRNA patterns in glioblastoma and Alzheimer's disease. Oncol. Rep. 2019, 42, 911-922. [CrossRef] [PubMed]

34. Lombardo, S.D.; Mazzon, E.; Basile, M.S.; Cavalli, E.; Bramanti, P.; Nania, R.; Fagone, P.; Nicoletti, F.; Petralia, M.C. Upregulation of IL-1 receptor antagonist in a mouse model of migraine. Brain Sci. 2019, 9, 172. [CrossRef] [PubMed]

35. Lombardo, S.D.; Presti, M.; Mangano, K.; Petralia, M.C.; Basile, M.S.; Libra, M.; Candido, S.; Fagone, P.; Mazzon, E.; Nicoletti, F.; et al. Prediction of PD-L1 expression in neuroblastoma via computational modeling. Brain Sci. 2019, 9, 221. [CrossRef]

36. Petralia, M.C.; Mazzon, E.; Fagone, P.; Falzone, L.; Bramanti, P.; Nicoletti, F.; Basile, M.S. Retrospective follow-up analysis of the transcriptomic patterns of cytokines, cytokine receptors and chemokines at preconception and during pregnancy, in women with post-partum depression. Exp. Ther. Med. 2019, 18, 2055-2062. [CrossRef]

37. Lombardo, S.D.; Mazzon, E.; Mangano, K.; Basile, M.S.; Cavalli, E.; Mammana, S.; Fagone, P.; Nicoletti, F.; Petralia, M.C. Transcriptomic analysis reveals involvement of the macrophage migration inhibitory factor gene network in duchenne muscular dystrophy. Genes 2019, 10, 939. [CrossRef] [PubMed]

38. Lombardo, S.D.; Mazzon, E.; Basile, M.S.; Campo, G.; Corsico, F.; Presti, M.; Bramanti, P.; Mangano, K.; Petralia, M.C.; Nicoletti, F.; et al. Modulation of tetraspanin 32 (TSPAN32) expression in T cell-mediated immune responses and in multiple sclerosis. Int. J. Mol. Sci. 2019, 20, 4323. [CrossRef]

39. Petralia, M.C.; Mazzon, E.; Basile, M.S.; Cutuli, M.; Di Marco, R.; Scandurra, F.; Saraceno, A.; Fagone, P.; Nicoletti, F.; Mangano, K. Effects of treatment with the hypomethylating agent 5-aza-2'-deoxycytidine in murine type II collagen-induced arthritis. Pharmaceuticals 2019, 12, 174. [CrossRef] [PubMed]

40. Fagone, P.; Mazzon, E.; Mammana, S.; Di Marco, R.; Spinasanta, F.; Basile, M.; Petralia, M.; Bramanti, P.; Nicoletti, F.; Mangano, K. Identification of CD4+ T cell biomarkers for predicting the response of patients with relapsing-remitting multiple sclerosis to natalizumab treatment. Mol. Med. Rep. 2019. [CrossRef] 
41. Nicoletti, F.; Mazzon, E.; Fagone, P.; Mangano, K.; Mammana, S.; Cavalli, E.; Basile, M.S.; Bramanti, P.; Scalabrino, G.; Lange, A.; et al. Prevention of clinical and histological signs of MOG-induced experimental allergic encephalomyelitis by prolonged treatment with recombinant human EGF. J. Neuroimmunol. 2019, 332, 224-232. [CrossRef]

42. Cavalli, E.; Mazzon, E.; Basile, M.S.; Mangano, K.; Di Marco, R.; Bramanti, P.; Nicoletti, F.; Fagone, P.; Petralia, M.C. Upregulated expression of macrophage migration inhibitory factor, its analogue D-dopachrome tautomerase, and the CD44 receptor in peripheral CD4 T cells from clinically isolated syndrome patients with rapid conversion to clinical defined multiple sclerosis. Medicina 2019, 55, 667. [CrossRef]

43. Cavalli, E.; Mazzon, E.; Basile, M.S.; Mammana, S.; Pennisi, M.; Fagone, P.; Kalfin, R.; Martinovic, V.; Ivanovic, J.; Andabaka, M.; et al. In silico and in vivo analysis of IL37 in multiple sclerosis reveals its probable homeostatic role on the clinical activity, disability, and treatment with fingolimod. Molecules 2019, 25, 20. [CrossRef]

44. Günther, S.; Fagone, P.; Jalce, G.; Atanasov, A.G.; Guignabert, C.; Nicoletti, F. Role of MIF and D-DT in immune-inflammatory, autoimmune, and chronic respiratory diseases: From pathogenic factors to therapeutic targets. Drug Discov. Today 2019, 24, 428-439. [CrossRef] [PubMed]

45. Basile, M.S.; Mazzon, E.; Mangano, K.; Pennisi, M.; Petralia, M.C.; Lombardo, S.D.; Nicoletti, F.; Fagone, P.; Cavalli, E. Impaired expression of tetraspanin 32 (TSPAN32) in memory T cells of patients with multiple sclerosis. Brain Sci. 2020, 10, 52. [CrossRef] [PubMed]

46. Fagone, P.; Mangano, K.; Mammana, S.; Cavalli, E.; Di Marco, R.; Barcellona, M.L.; Salvatorelli, L.; Magro, G.; Nicoletti, F. Carbon monoxide-releasing molecule-A1 (CORM-A1) improves clinical signs of experimental autoimmune uveoretinitis (EAU) in rats. Clin. Immunol. 2015, 157, 198-204. [CrossRef] [PubMed]

47. Cavalli, E.; Mazzon, E.; Mammana, S.; Basile, M.S.; Lombardo, S.D.; Mangano, K.; Bramanti, P.; Nicoletti, F.; Fagone, P.; Petralia, M.C. Overexpression of macrophage migration inhibitory factor and its homologue D-dopachrome tautomerase as negative prognostic factor in neuroblastoma. Brain Sci. 2019, 9, 284. [CrossRef]

48. Petralia, M.C.; Mazzon, E.; Fagone, P.; Russo, A.; Longo, A.; Avitabile, T.; Nicoletti, F.; Reibaldi, M.; Basile, M.S. Characterization of the pathophysiological role of CD47 in uveal melanoma. Molecules 2019, 24, 2450. [CrossRef]

49. Mangano, K.; Cavalli, E.; Mammana, S.; Basile, M.S.; Caltabiano, R.; Pesce, A.; Puleo, S.; Atanasov, A.G.; Magro, G.; Nicoletti, F.; et al. Involvement of the $\mathrm{Nrf} 2 / \mathrm{HO}-1 / \mathrm{CO}$ axis and therapeutic intervention with the CO-releasing molecule CORM-A1, in a murine model of autoimmune hepatitis. J. Cell. Physiol. 2018, 233, 4156-4165. [CrossRef] [PubMed]

50. Mammana, S.; Bramanti, P.; Mazzon, E.; Cavalli, E.; Basile, M.S.; Fagone, P.; Petralia, M.C.; McCubrey, J.A.; Nicoletti, F.; Mangano, K. Preclinical evaluation of the PI3K/Akt/mTOR pathway in animal models of multiple sclerosis. Oncotarget 2018, 9, 8263-8277. [CrossRef]

51. Mammana, S.; Fagone, P.; Cavalli, E.; Basile, M.S.; Petralia, M.C.; Nicoletti, F.; Bramanti, P.; Mazzon, E. The role of macrophages in neuroinflammatory and neurodegenerative pathways of Alzheimer's disease, amyotrophic lateral sclerosis, and multiple sclerosis: Pathogenetic cellular effectors and potential therapeutic targets. Int. J. Mol. Sci. 2018, 19, 831. [CrossRef]

52. Petralia, M.C.; Mazzon, E.; Fagone, P.; Basile, M.S.; Lenzo, V.; Quattropani, M.C.; Bendtzen, K.; Nicoletti, F. Pathogenic contribution of the Macrophage migration inhibitory factor family to major depressive disorder and emerging tailored therapeutic approaches. J. Affect. Disord. 2020, 263, 15-24. [CrossRef]

53. Fagone, P.; Mangano, K.; Mammana, S.; Pesce, A.; Pesce, A.; Caltabiano, R.; Giorlandino, A.; Rosanna Portale, T.; Cavalli, E.; Lombardo, G.A.G.; et al. Identification of novel targets for the diagnosis and treatment of liver fibrosis. Int. J. Mol. Med. 2015, 36, 747-752. [CrossRef]

54. Basile, M.; Mazzon, E.; Krajnovic, T.; Draca, D.; Cavalli, E.; Al-Abed, Y.; Bramanti, P.; Nicoletti, F.; Mijatovic, S.; Maksimovic-Ivanic, D. Anticancer and differentiation properties of the nitric oxide derivative of lopinavir in human glioblastoma cells. Molecules 2018, 23, 2463. [CrossRef]

55. Petralia, M.C.; Battaglia, G.; Bruno, V.; Pennisi, M.; Mangano, K.; Lombardo, S.D.; Fagone, P.; Cavalli, E.; Saraceno, A.; Nicoletti, F.; et al. The role of macrophage migration inhibitory factor in Alzheimer's disease: Conventionally pathogenetic or unconventionally protective? Molecules 2020, 25, 291. [CrossRef]

56. Mammana, S.; Cavalli, E.; Gugliandolo, A.; Silvestro, S.; Pollastro, F.; Bramanti, P.; Mazzon, E. Could the combination of two non-psychotropic cannabinoids counteract neuroinflammation? Effectiveness of cannabidiol associated with cannabigerol. Medicina 2019, 55, 747. [CrossRef]

57. Schepici, G.; Cavalli, E.; Bramanti, P.; Mazzon, E. Autism spectrum disorder and miRNA: An overview of experimental models. Brain Sci. 2019, 9, 265. [CrossRef]

58. Pardo, E.; Cárcamo, C.; Martín, R.U.S.; Ciampi, E.; Segovia-Miranda, F.; Curkovic-Peña, C.; Montecino, F.; Holmes, C.; Tichauer, J.E.; Acuña, E.; et al. Galectin-8 as an immunosuppressor in experimental autoimmune encephalomyelitis and a target of human early prognostic antibodies in multiple sclerosis. PLOS ONE 2017, 12, e0177472. [CrossRef] [PubMed]

59. Elola, M.T.; Ferragut, F.; Cárdenas Delgado, V.M.; Nugnes, L.G.; Gentilini, L.; Laderach, D.; Troncoso, M.F.; Compagno, D.; Wolfenstein-Todel, C.; Rabinovich, G.A. Expression, localization and function of galectin-8, a tandem-repeat lectin, in human tumors. Histol. Histopathol. 2014, 29, 1093-1105. [PubMed]

60. Thurston, T.L.M.; Wandel, M.P.; Von Muhlinen, N.; Foeglein, Á.; Randow, F. Galectin 8 targets damaged vesicles for autophagy to defend cells against bacterial invasion. Nature 2012, 482, 414-418. [CrossRef] [PubMed] 
61. Jia, J.; Abudu, Y.P.; Claude-Taupin, A.; Gu, Y.; Kumar, S.; Choi, S.W.; Peters, R.; Mudd, M.H.; Allers, L.; Salemi, M.; et al. Galectins control mTOR in response to endomembrane damage. Mol. Cell 2018, 70, 120-135. [CrossRef] [PubMed]

62. Staring, J.; Von Castelmur, E.; Blomen, V.A.; Van Den Hengel, L.G.; Brockmann, M.; Baggen, J.; Thibaut, H.J.; Nieuwenhuis, J.; Janssen, H.; Van Kuppeveld, F.J.M.; et al. PLA2G16 represents a switch between entry and clearance of Picornaviridae. Nature 2017, 541, 412-416. [CrossRef] [PubMed]

63. Falcon, B.; Noad, J.; McMahon, H.; Randow, F.; Goedert, M. Galectin-8-mediated selective autophagy protects against seeded tau aggregation. J. Biol. Chem. 2018, 293, 2438-2451. [CrossRef]

64. Cárcamo, C.; Pardo, E.; Oyanadel, C.; Bravo-Zehnder, M.; Bull, P.; Cáceres, M.; Martínez, J.; Massardo, L.; Jacobelli, S.; González, A.; et al. Galectin- 8 binds specific $\beta 1$ integrins and induces polarized spreading highlighted by asymmetric lamellipodia in Jurkat T cells. Exp. Cell Res. 2006, 312, 374-386. [CrossRef]

65. Norambuena, A.; Metz, C.; Vicuña, L.; Silva, A.; Pardo, E.; Oyanadel, C.; Massardo, L.; González, A.; Soza, A. Galectin-8 induces apoptosis in Jurkat T cells by phosphatidic acid-mediated ERK1/2 activation supported byprotein kinase A down-regulation. J. Biol. Chem. 2009, 284, 12670-12679. [CrossRef]

66. Levy, Y.; Arbel-Goren, R.; Hadari, Y.R.; Eshhar, S.; Ronen, D.; Elhanany, E.; Geiger, B.; Zick, Y. Galectin-8 functions as a matricellular modulator of cell adhesion. J. Biol. Chem. 2001, 276, 31285-31295. [CrossRef]

67. Pardo, E.; Barake, F.; Godoy, J.A.; Oyanadel, C.; Espinoza, S.; Metz, C.; Retamal, C.; Massardo, L.; Tapia-Rojas, C.; Inestrosa, N.C.; et al. Galectin-8 is a neuroprotective factor in the brain that can be neutralized by human autoantibodies. Mol. Neurobiol. 2019, 56, 7774-7788. [CrossRef] [PubMed]

68. Katsel, P.; Davis, K.L.; Gorman, J.M.; Haroutunian, V. Variations in differential gene expression patterns across multiple brain regions in schizophrenia. Schizophr. Res. 2005, 77, 241-252. [CrossRef] [PubMed]

69. Haroutunian, V.; Katsel, P.; Dracheva, S.; Stewart, D.G.; Davis, K.L. Variations in oligodendrocyte-related gene expression across multiple cortical regions: Implications for the pathophysiology of schizophrenia. Int. J. Neuropsychopharmacol. 2007, 10, 565-573. [CrossRef] [PubMed]

70. Kumar, A.; Pareek, V.; Singh, H.N.; Faiq, M.A.; Narayan, R.K.; Raza, K.; Kumar, P. Altered expression of a unique set of genes reveals complex etiology of schizophrenia. Front. Psychiatry 2019, 10, 906. [CrossRef] 